\title{
How Stale Central Bank Interest Rate Projections Affect Interest Rate Uncertainty
}

\section{Gunda-Alexandra Detmers and Dieter Nautz*}

The Reserve Bank of New Zealand manages market expectations via interest rate projections that are updated only quarterly. Consequently, projections may become stale when new information enters the market. We investigate the time-varying and state-dependent impact of interest rate projections. Confirming the stabilizing effect of fresh central bank announcements, we show that interest rate uncertainty rises between two projection releases. Moreover, interest rate uncertainty increases if market expectations increasingly deviate from the rate projected by the central bank. Counterfactual analysis suggests that the efficiency of projections would improve if the central bank updated its projection whenever it becomes stale.

Keywords: Central bank interest rate projections, central bank communication, quantitative forward guidance, interest rate uncertainty.

JEL classification: E52, E58

\footnotetext{
*Nautz is Professor of Economics and Detmers is Research Assistant at Freie Universität Berlin. Financial support by the German Research Foundation through the CRC 649 Economic Risk is gratefully acknowledged. We are thankful for comments and suggestions received from seminar participants at the Goethe-University Frankfurt, the Freie Universität Berlin, the Reserve Bank of New Zealand and from conference participants at at Viessmann European Research Centre, Waterloo, Canada. E-mail: gunda-alexandra.detmers@fu-berlin.de; dieter.nautz@fu-berlin.de
} 


\section{Introduction}

The efficiency of monetary policy crucially depends on the central bank's expectations management, see Blinder et al. (2008). The growing literature on central bank communication suggests that publication of interest rate projections can be a powerful tool for both explaining monetary policy and guiding market expectations, see e.g. Rudebusch and Williams (2008). The Reserve Bank of New Zealand (RBNZ) was the first central bank to publish projections of the future 90-day bank bill rate so as to guide interest rate expectations up to three years in the future. The information content of central bank interest rate projections is typically investigated in event studies that focus on the projection's impact on market rates at or close to the announcement day, see Moessner and Nelson (2008), Ferrero and Secchi (2009), Detmers and Nautz (2012), Moessner (2013) and Winkelmann (2013) 1 However, the RBNZ's projections are published and updated only quarterly 2 As a consequence, projections can become easily stale over time and when new information enters the market. Since the remaining information content of a projection is not obvious, stale projections may even undermine the transparency of monetary policy and the expectations management of the central bank. This paper sheds new light on the empirical performance of the RBNZ's forward guidance by estimating the time-varying and state-dependent impact of projections on interest rate uncertainty.

\footnotetext{
${ }^{1}$ In the same vein, Swanson (2006) shows that interest rate uncertainty in the United States typically decreases on the day of FOMC announcements. Bauer (2012) uses an event study to demonstrate that the FED's forward guidance during the financial crisis both shifted the expected path of the federal funds rate and reduced uncertainty surrounding those expectations.

${ }^{2} \mathrm{~A}$ similar timing has been adopted by several other central banks, including the Norges Bank and the Sveriges Riksbank, see e.g. Andersson and Hofmann (2010).
} 
There continues to be debate over the utility of regularly announced interest rate projections for central bank communication. Goodhart and Wen (2011) conclude from a forecast analysis that the RBNZ's interest rate projections are useless for a horizon of more than two quarters ahead. According to Neuenkirch (2012), publication of interest rate projections contributes to a high transparency index of the RBNZ which is found to reduce the bias and variation of expectations. However, none of these contributions consider the time-varying information content of interest rate projections. Therefore, our paper is most closely related to Ehrmann and Sondermann (2012), who investigate the time-varying news content of the quarterly Bank of England Inflation Report. They find that interest rate uncertainty rises over time until the central bank updates its communication.

\section{Following Ehrmann and Sondermann (2012), we explore the impact of interest rate} projections on interest rate uncertainty within an EGARCH framework for daily changes in market interest rates of various maturities. In our application, the relevant market rate is the futures rate whose maturity exactly matches the rate projected by the central bank. The spread between these interest rates reveals the extent to which market expectations continue to rely on the projection. Specifically, large spreads indicate that the projection has become stale. The empirical model is used to test two hypotheses on the time- and state-dependent impact of interest rate projections on market expectations. Hypothesis 1 is that interest rate uncertainty increases between two releases of central bank projections. According to Hypothesis 2, large spreads implying stale projections contribute to higher interest rate uncertainty. In particular, the uncertainty-increasing 
impact of stale projections becomes stronger the longer markets have to wait for an updated projection.

Both hypotheses on the time- and state-dependent impact of central bank projections on interest rate uncertainty are confirmed by the data. Our empirical results therefore suggest that the efficiency of interest rate projections could be improved by the central bank along two dimensions. First, projections would be more useful if they were updated more frequently. Second, the central bank should update its projection whenever markets perceive the current projection to be stale. In fact, counterfactual analysis suggests that the performance of the RBNZ's projections could improve significantly by using a more flexible, state-dependent implementation scheme that ensures a certain freshness of the projections.

The rest of the paper is organized as follows. In the next section, we present the RBNZ's interest rate projections and the data. Section 3 discusses the volatility effects of stale projections. Section 4 introduces the econometric model and the estimation results. Section 5 provides a counterfactual analysis of alternative implementation schemes for interest rate projections. Section 6 offers some concluding remarks. 


\section{The Interest Rate Projections of the RBNZ and Market}

\section{Expectations}

Since 1997, the RBNZ has been projecting the 90-day bank bill rate for the following 8 to 12 quarters. These projections are published in the RBNZ's Monetary Policy Statement (MPS) 3 Figure 1 shows that interest rate projections change substantially from one release to the next, a first clue that projections lose much of their relevance over the course of a quarter.

Figure 1 Interest rate projections and the 90-day interest rate

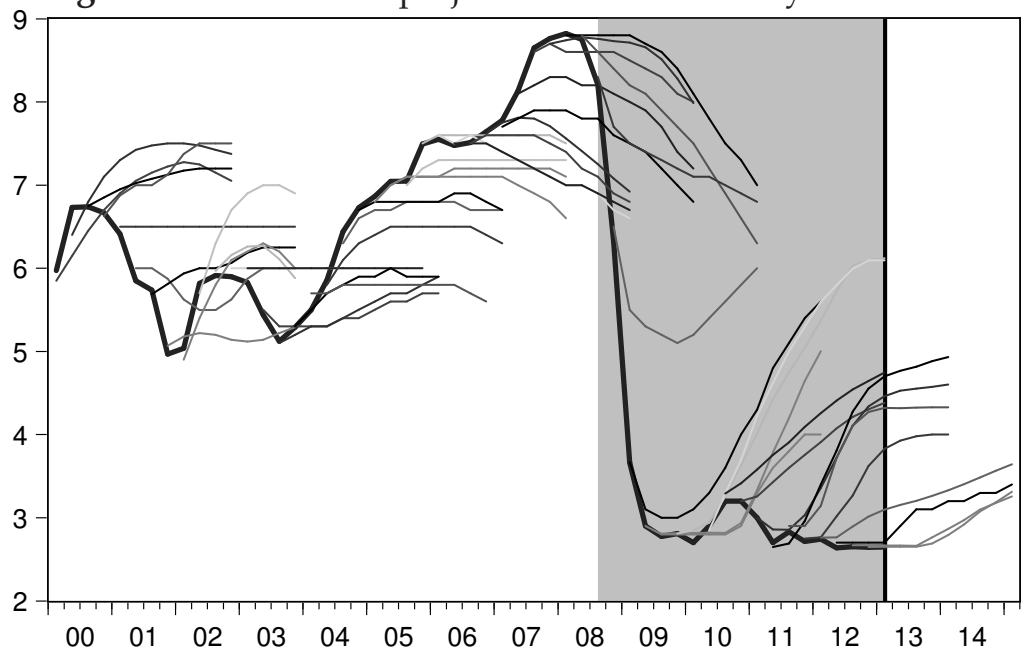

Notes: Quarterly projections for the 90-day bank bill rate around its actual monthly level (continuous bold line). The light shaded area refers to the period as of September 2008. The vertical line represents the end of the sample. Data are taken from the Monetary Policy Statements of the RBNZ from March 2000 through February 2013. Source: Detmers and Nautz (2012)

Interest rate projections are published quarterly and are, thus, by construction constant between two publication days. This implies, however, that the actual projection

\footnotetext{
${ }^{3}$ For a comprehensive introduction to the RBNZ's monetary policy framework of the RBNZ, see e.g. Guender and Rimer (2008).
} 
horizon is not constant but shrinks in the course of a quarter. For example, the maturity of a projection for $j$ quarters ahead has declined to virtually $j-1$ quarters when the next projection is about to be published. Therefore, we adjust the quarterly projection data in order to obtain daily data for projections with a constant maturity of $j$ quarters. Note that the maturity-adjusted projection $p_{t}^{j}$ employed in the empirical analysis increasingly incorporates information from the projection for $j+1$ quarters ahead 4 As a consequence, $p_{t}^{j}$ is not necessarily constant between two publications, compare Figure 2 and the time series plots in the data appendix.

We use futures rates on the 90-day bank bill rate $j$ quarters ahead as a proxy for prevailing market expectations about future interest rates. The empirical analysis is restricted to $j=1, \ldots, 5$ since data for longer-term futures rates are available only from 2007 onward. Following Detmers and Nautz (2012), futures rates are adjusted in order to obtain data with constant maturity, $f_{t}^{j}$, that exactly match the maturity of the corresponding projection rate $p_{t}^{j}$.

If $f_{t}^{j}$ is close to $p_{t}^{j}$, market expectations are in line with the central bank projection suggesting that the perceived information content of the current projection is still high. Yet, new information might lead markets to expect the future interest rate to differ from the current central bank projection. In this case, the information content of the projection has become stale and $f_{t}^{j}$ should deviate from $p_{t}^{j}$. Our sample period runs from March 1, 2000 until February 28, 2013 5

\footnotetext{
${ }^{4}$ Specifically, daily data for the maturity-adjusted $p_{t}^{j}$ is obtained as a weighted average of the two corresponding unadjusted interest rate projections, where the weight of the projection for $j+1$ quarters ahead rises linearly over time.

${ }^{5}$ The sample period does not start already in 1997 because of data availability problems for some control
} 
Table 1 Absolute deviation of futures rates from central bank projections

\begin{tabular}{lccccc}
\hline maturity in quarters & $\mathrm{j}=1$ & $\mathrm{j}=2$ & $\mathrm{j}=3$ & $\mathrm{j}=4$ & $\mathrm{j}=5$ \\
\hline \hline pre-crisis: March 1, 2000 - Sep & 12,2008 & & & & \\
\hline mean $\left(\left|f^{j}-p^{j}\right|\right)$ & 27.01 & 33.42 & 40.95 & 46.45 & 49.57 \\
median $\left(\left|f^{j}-p^{j}\right|\right)$ & 16.74 & 24.39 & 31.26 & 36.61 & 37.39 \\
\hline crisis: Sep 15, 2008 - Feb 28, 2013 & & & & \\
\hline mean $\left(\left|f^{j}-p^{j}\right|\right)$ & 39.98 & 53.30 & 66.37 & 74.35 & 75.76 \\
median $\left(\left|f^{j}-p^{j}\right|\right)$ & 19.38 & 31.90 & 48.94 & 55.48 & 55.52 \\
\hline \hline
\end{tabular}

Notes: Mean and median are denoted in basis points. Sample ranges from March 2000 through February 2013 and is separated into the pre-crisis and crisis period starting with the Lehman failure on September 15, 2008.

For each maturity, the sizable difference between the mean and the median of the absolute deviation between futures rates and the corresponding interest rate projections indicate the presence of outliers (see Table 1 and Figure 3 in the Appendix). As expected, average deviations rise with increasing maturity and are higher during the financial crisis, defined as starting with the Lehman failure in September 2008.

\section{Stale Interest Rate Projections}

The RBNZ's interest rate projections are released every three months and are not updated between releases. Typically, futures rates are roughly in line with the central bank interest rate projection, at least shortly after the release of a new interest rate path. However, over time, market expectations often start to deviate from the central bank

variables, see Appendix. Moreover, our sample avoids a structural break due to changes in the RBNZ's monetary policy framework in 1999, compare Guender and Rimer (2008). 
projection, implying that its information content has decreased. Since the degree of its staleness is not clear, markets are confronted with a signal-extraction problem. In this section, we propose two testable hypotheses about the volatility effects of probably stale interest rate projections.

\section{Hypothesis 1 Interest rate uncertainty rises between two interest rate projections.}

When the most recent projection ages, markets cannot be sure of its continuing relevance, especially since the central bank does not comment on the projection once it has been published. Therefore, regardless of expectations prevalent in the market, the information content of a projection declines over time, implying increasing interest rate uncertainty until the new projection is published.

Hypothesis 2 Interest rate uncertainty rises if markets believe the recent interest rate projection to be stale, i.e. if the rate expected by the market increasingly deviates from the rate projected by the central bank. The effect of stale projections on interest rate uncertainty becomes stronger the longer markets have to wait for an updated projection.

Figure 2 shows the development of a central bank interest rate projection and market expectations after projection's release on September 4, 2003. Although interest rate expectations are in line with the central bank interest rate projection in the days just following the publication, expectations begin to diverge after about 20 business days. Apparently, with new information entering the market, the recent interest rate projection loses its information content. In this case, market expectations about the future interest rate path deviate from the stale central bank projection and interest rate uncer- 
Figure 2 An interest rate projection that becomes stale

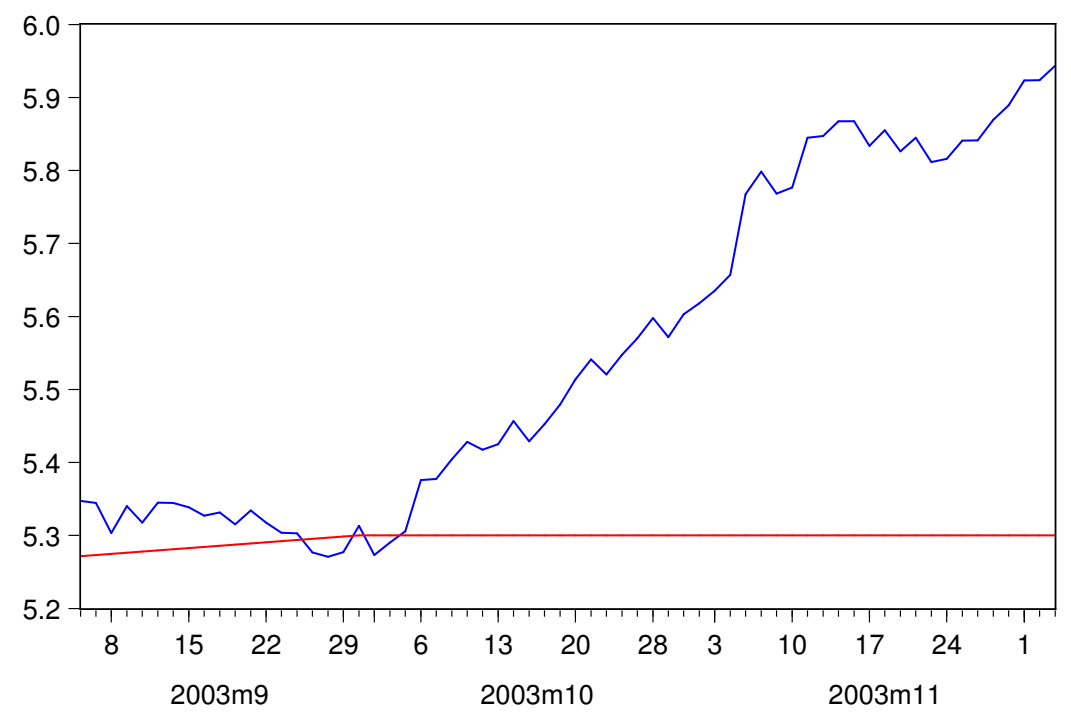

Notes: The Figure shows the RBNZ's interest rate projection for $j=1$ (bold line) and the corresponding futures rate between the two interest rate projections of the third and fourth quarter of 2003. The increased spread indicates that markets eventually perceive the central bank projection to be outdated.

tainty should rise. However, in line with Hypothesis 2, we expect markets to distinguish between a deviation of futures rates from the central bank projection observed at the beginning of a quarter and the deviation observed at the end of a quarter such that the deviation will matter less the older the recent projection.

\section{The Impact of Projections on Interest Rate Uncertainty:}

\section{Empirical Results}

Market expectations about the future 90-day bank bill rate $j$ quarters ahead are reflected in $f_{t}^{j}$. Following Ehrmann and Sondermann (2012), we model the daily change in ex- 
pectations by

$$
\Delta f_{t}^{j}=\alpha^{j}+\delta^{j} \Delta f_{t-1}^{j}+\gamma^{x, j} X_{t}+\varepsilon_{t}^{j}
$$

where $X_{t}$ represents a vector of control variables, including e.g. measures of monetary policy surprises, U.S. interest rates, the effective exchange rate, and an economic surprise index for New Zealand 6

For each $j=1, \ldots, 5$, the conditional variance of the futures rate is assumed to follow an augmented EGARCH(1,1) model:

$$
\begin{aligned}
\log \left(\sigma_{t}^{2, j}\right)= & \omega_{0}^{j}+\omega_{1}^{j} \cdot \log \left(\sigma_{t-1}^{2, j}\right)+\omega_{2}^{j} \cdot\left|\frac{\varepsilon_{t-1}^{j}}{\sigma_{t-1}^{j}}\right|+\omega_{3}^{j} \cdot \frac{\varepsilon_{t-1}^{j}}{\sigma_{t-1}^{j}} \\
& +\rho_{\tau}^{j} \tau_{t}+\rho_{s}^{j}\left|f^{j}-p^{j}\right|_{t-1}\left(1-\tau_{t}\right)+\rho_{z}^{j} Z_{t}
\end{aligned}
$$

where $Z_{t}$ represents a vector of dummies controlling for monetary policy days. The variable $\tau_{t}$ measures the time elapsed since the last release of an interest rate projection. Specifically, we calculate $0 \leq \tau_{t} \leq 1$ as the number of days since the last release divided by the total number of days between the preceding and the subsequent release of RBNZ's interest rate projections. Thus, $\tau_{t}$ equals 0 on the announcement day and 1 on the day before the subsequent announcement.

According to Hypothesis 1, uncertainty should rise over time until the next projection is published, implying that $\rho_{\tau}^{j}>0 . \rho_{s}^{j}$ indicates the state dependency of a projection's

\footnotetext{
${ }^{6}$ For more information about the controls, see Table 6 in the Appendix.
} 
information content. Following Hypothesis 2, the variance increases the more interest rate expectations deviate from the central bank projection, implying that $\rho_{s}^{j}>0$. Since this effect decreases over time, we interact $\rho_{s}^{j}>0$ with $\left(1-\tau_{t}\right)$.

The role of $\tau_{t}$ for the time- and state-dependent effects of projections on interest rate uncertainty can be illustrated by two alternative specifications for the time variable. Suppose, for example, $\tau$ would be zero at each day of the quarter. In this case, staleness of projections would not be an issue because the current projection is always new. This also implies, however, that the probably distorting impact of deviatons of market expectations from projections, $\left(1-\tau_{t}\right)\left(f^{j}-p^{j}\right)$, does not vanish over time. In contrast, if $\tau$ equaled one throughout the quarter, the information content of projections would always be negligible.

Table 2 summarizes the results from the estimation of the $\operatorname{EGARCH}(1,1)$ from Equation (2) for the period from March 1, 2000 until February 28, 2013. The complete set of results is provided in the Appendix. Following Detmers and Nautz (2012), we separated the sample into the pre-crisis and crisis period, which is defined to start with the Lehman failure on September 15, 2008.

In line with Hypothesis 1, in both periods interest rate uncertainty typically increases with time elapsing since the most recent published projection $\left(\rho_{\tau}^{j}>0\right)$. The only exception is the insignificant estimate of $\rho_{\tau}^{5}=-0.01$ obtained for the pre-crisis period. In all other cases, an aging projection induces higher market uncertainty. Put differently, this effect confirms the usefulness of projections, since volatility is lower when the pro- 
Table 2 Interest rate volatility and stale interest rate projections

\begin{tabular}{lccccc}
\hline \hline maturity in quarters & $\mathrm{j}=1$ & $\mathrm{j}=2$ & $\mathrm{j}=3$ & $\mathrm{j}=4$ & $\mathrm{j}=5$ \\
\hline \multicolumn{2}{l}{ pre-crisis: March 1, 2000} & Sep 12, 2008 \\
& $0.30^{* * *}$ & $0.19^{* * *}$ & $0.18^{* * *}$ & 0.05 & -0.01 \\
$\rho_{\tau}^{j}$ & $(0.05)$ & $(0.05)$ & $(0.06)$ & $(0.06)$ & $(0.07)$ \\
& $1.98^{* * *}$ & $1.33^{* * *}$ & $1.25^{* * *}$ & $0.72^{* * *}$ & $0.49^{* * *}$ \\
$\rho_{s}^{j}$ & $(0.19)$ & $(0.11)$ & $(0.12)$ & $(0.09)$ & $(0.08)$ \\
& & & & & \\
\hline \hline
\end{tabular}

crisis: Sep 15, 2008 - Feb 28, 2013

\begin{tabular}{cccccc}
\hline$\rho_{\tau}^{j}$ & $0.26^{* * *}$ & $0.25^{* * *}$ & $0.24^{* * *}$ & $0.20^{* * *}$ & $0.15^{* * *}$ \\
$\rho_{s}^{j}$ & $(0.05)$ & $(0.05)$ & $(0.05)$ & $(0.06)$ & $(0.04)$ \\
& $0.52^{* * *}$ & $0.44^{* * *}$ & $0.31^{* * *}$ & $0.25^{* * *}$ & $0.19^{* * *}$ \\
\hline \hline
\end{tabular}

Notes: The table shows the empirical results from equation [2]. The sample covers all business days from March 1, 2000 until September 12, 2008 for the pre-crisis period and from September 15, 2008 until February 28, 2013 for the crisis period. ${ }^{* * *}\left(^{* *}\right)\left[{ }^{*}\right]$ denotes significance at the $1 \%$ (5 $\%)[10 \%]$ level, standard errors in parentheses. For the complete set of results, refer to Tables 4 and 5 in the appendix.

jection was recently announced. While a significant time dependence is found only for short maturities up to three quarters in the pre-crisis period, this effect is highly significant for all maturities in the crisis period. This may indicate that the information content of longer-term projections was limited until September 2008. Since the crisis, however, newly announced interest rate projections dampen even the volatility of longer-term futures rates.

Confirming Hypothesis 2, we find a significant state-dependent effect $\left(\rho_{s}^{j}>0\right)$ of projections on interest rate volatility. When interest rate expectations increasingly deviate from the corresponding interest rate projection, their information content declines and interest rate uncertainty rises. However, this effect shrinks over time, i.e. when 
the projection becomes older. Apparently, markets understand that with increasing age of the recent projection, deviations from it matter less. Large spreads between market expectations and interest rate projections at the end of a quarter induce less market uncertainty than a few days after a new publication. For both sample periods, the strength of the state-dependent effect declines with the horizon $j$, suggesting that the information content of projections is higher for short maturities. Note that the size of the state-dependent coefficients is not easily comparable across sample periods. Specifically, the smaller coefficients estimated for the crisis period do not necessarily imply less state-dependence since the deviations between futures rates and the central bank projections are typically more pronounced in the aftermath of the Lehman failure.

The estimation results suggest that central bank interest rate projections are a powerful tool for guiding market expectations, but they could be used more efficiently. First, interest rate projections could be provided more frequently instead of only quarterly, with daily updated projections as a limiting case. Alternatively, the central bank could update its projections whenever current events cast doubt on the information content and validity of the extant projection. Once market expectations and central bank projections diverge too far, the central bank could adjust its projection (if the bank follows market expectations) or reestablish the validity of the current projection (if market expectations were incorrect). In any case, the difference between market expectations and the central bank projection $(|f-p|)$ should decline. 


\section{Counterfactual Analysis of Alternative Projection}

\section{Implementation Schemes}

The results presented in Section 4 suggest that the central bank could lower interest rate uncertainty by maintaining the freshness of projections. In this section, we propose a counterfactual analysis in order to evaluate the volatility effects of alternative implementation schemes for central bank projections. To that end, consider the following implementation schemes:

(1) Projections with daily update: The central bank announces its interest rate projections on a daily basis. Accordingly, staleness of projections is not an issue and market expectations should be in line with projections. In the counterfactual analysis, this scenario implies that $\left|\widetilde{f^{j}-p^{j}}\right| \equiv 0$ and $\widetilde{\tau_{t}} \equiv 0$.

(2) No projections: As a further limiting case, suppose that the central bank provides no interest rate projections. In this case, we assume that $\widetilde{\tau_{t}} \equiv 1$ and projections have no impact on interest rate volatility.

(3) Projections with state-dependent update: The central bank announces a new projection (or reinforces the current one) whenever $\left|f^{j}-p^{j}\right|$ rises above a certain thresh-

old $S$. In this scenario, market expectations should be constrained by a band of $2 \cdot S$ basis points around the projection. In the counterfactual analysis, this implementation scheme implies that $\left|\widetilde{f^{j}-p^{j}}\right| \leq S$. Since the central bank is paying constant attention to when the projection needs to be updated, time-varying effects of pro- 
jections on interest rate uncertainty should be negligible, i.e. $\widetilde{\tau_{t}} \equiv 0$.

The counterfactual volatilities for the above three schemes are based on the normalized residuals of the EGARCH models estimated for each maturity and sample period. We obtain the counterfactual conditional volatility $\widetilde{\sigma}_{t}^{2, j}$ via a dynamic simulation of the estimated variance equation:

$$
\begin{aligned}
\log \left(\widetilde{\sigma}_{t}^{2, j}\right)= & \hat{\omega}_{o}^{j}+\hat{\omega}_{1}^{j} \cdot \log \left(\widetilde{\sigma}_{t-1}^{2, j}\right)+\hat{\omega}_{2}^{j} \cdot \frac{\left|\frac{\hat{\varepsilon}_{t-1}^{j}}{\mid \hat{\sigma}_{t-1}^{j}}\right|+\hat{\omega}_{3}^{j} \cdot \frac{\hat{\varepsilon}_{t-1}^{j}}{\hat{\sigma}_{t-1}^{j}}}{}+\hat{\rho}^{z, j} Z_{t}+\hat{\rho}_{\tau}^{j} \cdot \widetilde{\tau}_{t}+\hat{\rho}_{s}^{j} \cdot\left|f^{j-p^{j}}\right|_{t-1}\left(1-\widetilde{\tau}_{t}\right)
\end{aligned}
$$

Depending on the implementation scheme, we replace the original $\tau_{t}$ that ranges between $[0,1]$ by $\widetilde{\tau}_{t} \equiv 0$ (for the implementation schemes with updates) or $\widetilde{\tau}_{t} \equiv 1$ (for the limiting case without projections). Accordingly, the counterfactual values of $|f-p|$ are defined as $|\widetilde{f-p}|=\min \{|f-p|, S\}$, where $S=0,0.125,0.25$ defines the threshold value that triggers an update of the projection. For the scenario of daily updated projections, the threshold $S$ equals 0 . Central banks usually change interest rates in steps of 25 or 50 basis points. For the state-dependent projection updates, therefore, we use thresholds of 12.5 and 25 basis points. The size of the threshold reflects the degree of the central bank's aversion against stale projections.

Table 3 summarizes the results from the counterfactual analysis. The first row shows for each horizon, the median of the conditional standard deviation of futures rates estimated for the current practice of quarterly projections. As expected, interest rate uncertainty increases with the projection horizon $j$ and is larger since the financial crisis 
Table 3 Counterfactual analysis of alternative projection implementation schemes

\begin{tabular}{|c|c|c|c|c|c|c|c|c|c|c|}
\hline \multirow[b]{2}{*}{ Implementation scheme $\backslash$ maturity } & \multicolumn{5}{|c|}{ pre-crisis period } & \multicolumn{5}{|c|}{ crisis period } \\
\hline & $j=1$ & $j=2$ & $j=3$ & $j=4$ & $j=5$ & $j=1$ & $j=2$ & $j=3$ & $j=4$ & $j=5$ \\
\hline $\begin{array}{l}\text { Projections with quarterly update } \\
\qquad \hat{\sigma}\left(\left|f^{j}-p^{j}\right|\right)\end{array}$ & 2.71 & 3.16 & 3.35 & 3.54 & 3.77 & 3.05 & 4.22 & 4.99 & 5.22 & 5.50 \\
\hline $\begin{array}{l}\text { (1) Projections with daily update } \\
\qquad \widetilde{\sigma}\left(\left|f^{j}-p^{j}\right| \equiv 0, \widetilde{\tau}_{t} \equiv 0\right)\end{array}$ & 2.04 & 2.42 & 2.57 & 2.92 & 3.31 & 1.30 & 2.08 & 2.62 & 3.04 & 3.51 \\
\hline $\begin{array}{l}\text { (2) No projections } \\
\widetilde{\sigma}\left(\widetilde{\tau}_{t} \equiv 1\right)\end{array}$ & 2.60 & 2.91 & 3.00 & 3.07 & 3.35 & 3.78 & 4.52 & 5.28 & 5.34 & 5.60 \\
\hline $\begin{array}{l}\text { (3a) Projections with state-dependent update } \\
\widetilde{\sigma}\left(\min \left\{\left|f^{j}-p^{j}\right|, 12.5\right\}, \widetilde{\tau}_{t} \equiv 0\right)\end{array}$ & 2.42 & 2.78 & 2.89 & 3.19 & 3.52 & 1.66 & 2.44 & 2.91 & 3.31 & 3.76 \\
\hline $\begin{array}{l}\text { (3b) Projections with state-dependent update } \\
\widetilde{\sigma}\left(\min \left\{\left|f^{j}-p^{j}\right|, 25\right\}, \widetilde{\tau}_{t} \equiv 0\right)\end{array}$ & 2.74 & 3.12 & 3.19 & 3.44 & 3.71 & 1.93 & 2.78 & 3.17 & 3.58 & 4.00 \\
\hline
\end{tabular}

Notes: The table shows the medians of the estimated standard deviations of futures rates in basis points in the first row. The corresponding counterfactual standard deviations based on Equation (3) are presented in the subjacent rows. The sample starts on March 15, 2000 for the pre-crisis period and on December 12, 2008 for the crisis period which are the respective first monetary policy days in each period. The starting date is the first monetary policy day with a published projection in both subperiods where $\tau_{t}$ equals zero by definition, i.e. March 15, 2000 and December 4, 2008. 
began. All remaining rows show counterfactual standard deviations resulting from hypothetical implementation schemes for the central bank's interest rate projections.

Row 2 of Table 3 presents the counterfactual interest rate volatility for the limiting case of daily projection updates. Since daily projections imply $|\widetilde{f-p}|_{t-1} \equiv 0$ and $\widetilde{\tau_{t}} \equiv 0$, the resulting counterfactual volatility is by construction always lower than the estimated volatility under quarterly projections. In fact, the counterfactual standard deviations obtained for daily projections define a lower bound for the interest rate volatility for each alternative implementation scheme and give an idea of the enhancement potential of modifying the implementation schedule. The second row implies that this gain — reflected in the difference between volatilities obtained for projections with quarterly and daily updates — has remarkably increased both in absolute and relative terms since the outbreak of the crisis. The differences range between 0.46 and 0.78 basis points before and 1.75 and 2.37 basis points during the crisis period. In relative terms, the counterfactual interest rate volatility resulting from daily projections would have improved by $12-25 \%$ and $36-57 \%$ in the two sample periods compared to quarterly projections.

Counterfactual interest rate uncertainty will always decrease moving from quarterly to daily projection updates; however, the consequences for the counterfactual interest rate volatility of moving to the other extreme case of providing no projections are not obvious. On the one hand, interest rate uncertainty may increase because the volatilitydampening effect of fresh projections no longer applies, i.e. $\widetilde{\tau}_{t} \equiv 1$. On the other hand, however, the potential volatility-increasing effect of stale projections (as reflected 
in large values of $\left|f^{j}-p^{j}\right|$ ) also disappears. Therefore, interest rate projections can guide market expectations and decrease interest rate volatility only as long as the central bank ensures that projections do not become too stale. Looking at the counterfactual standard deviations of the no-projection scenario presented in Row 3 of Table 3 shows that the empirical performance of the RBNZ's quarterly projections is very different before and during the crisis. In the pre-crisis period, counterfactual standard deviations of the no-projection scenario are lower than the estimated standard deviations. This suggests that the RBNZ's quarterly projections were often too stale in the pre-crisis period. Apparently, the deviations of futures rates from the corresponding projection were too large and thus contributed to even more interest rate uncertainty. In contrast, the volatility-decreasing effects of quarterly projections dominate in the crisis period. For all horizons, the estimated standard deviations for quarterly projections are lower than their counterfactual counterparts obtained for the no-projection scenario. Interestingly, the volatility-decreasing effects of the RBNZ's projections become larger the shorter the projection horizon. This may suggest that forward guidance is more effective for short horizons.

Rows 4 and 5 of Table 3 show the counterfactual standard deviations of two variants of a more flexible, state-dependent implementation scheme for central bank interest rate projections. In these scenarios, the central bank updates its projection whenever the market perceives the current projection as being stale, i.e. whenever $\left|f^{j}-p^{j}\right|$ exceeds a certain threshold $S$. In practice, this can be accomplished by adjusting the projection to market expectations (if market expectations are correct) or by confirming the current 
projection (if market expectations are wrong). Since the deviations of futures rates from the corresponding projections are significantly larger, the volatility dampening effects of thresholds can be expected to be more pronounced in the crisis period (cf. Table 1). The counterfactual analysis confirms that interest rate volatility would have been significantly lower if projections had been issued more flexibly during the crisis period. Even for a large threshold ( $S=25)$, interest rate volatility decreases remarkably, implying volatility gains close to the first best scenario of daily projections. By contrast, in the pre-crisis period, the introduction of only a small threshold of $12.5 \mathrm{bp}$ has a significant volatility-decreasing effect, while the volatility gains of a large threshold remain negligible. For both periods, the efficiency of the RBNZ's interest rate projections could have been improved by employing the more flexible, state-dependent implementation scheme where a certain degree of freshness of projections is ensured.

\section{Concluding remarks}

Following the RBNZ's lead, central banks increasingly use interest rate projections to guide market expectations about the future course of monetary policy. To date, these projections have been implemented fairly inflexibly: regardless of the market's demand for forward guidance, projections are announced and updated only once a quarter. As a consequence, projections can become stale when new information enters the economy. Since the remaining information content of a probably stale projection is not obvious for financial markets, the overall effect of quarterly projections on the central bank's 
expectations management and, thus, on interest rate uncertainty is not clear.

This paper provides evidence on the time-varying and state-dependent impact of interest rate projections on the expectations management of central banks. Confirming the stabilizing effect of fresh central bank announcements, we show that interest rate uncertainty increases with the time elapsing since the most recent interest rate projection. Moreover, we find that market uncertainty significantly increases when projections become stale. Specifically, interest rate volatility rises whenever market expectations increasingly deviate from the rate projected by the central bank.

For the RBNZ, counterfactual analysis suggests that stale projections even slightly increased average interest rate volatility in the pre-crisis period. This already indicates that central banks could use interest rate projections more effectively. Our results demonstrate that central bank expectations management can be more efficient, if interest rate projections are updated whenever futures rates reveal that markets perceive the current projection as stale. In principle, this can be accomplished by adjusting the projection to market expectations (if expectations are correct) or by confirming the current projection (if expectations are wrong).

Our results show that interest rate projections can be a powerful tool for guiding market expectations provided that the central bank can ensure that the information content of projections remains sufficiently high. By contrast, stale projections may even pose an obstacle to central bank expectations management because they probably confuse markets and thus increase interest rate uncertainty. 
In monetary policy practice, preventing projections from becoming stale is not easy, particularly if the projections are updated only quarterly. However, since the preparation of interest rate projections involves the analysis of various complex quantitative models, providing projections 'on demand' is not a realistic policy option. This particularly applies for central banks like the ECB and the FED where each new projection would require the approval by a committee. In an attempt to ameliorate the problem of stale projections, the Sveriges Riksbank publishes alternative scenarios for the future interest rate path in its monetary policy report. The detailed discussion of various economic risks and their impact on the future interest rate path should help markets to assess to what extent a certain interest rate projection has become stale. 


\section{References}

Andersson, M. and Hofmann, B. (2010). Twenty Years of Inflation Targeting: Lessons Learned and Future Prospects, chapter "Gauging the effectiveness of quantitative forward guidance: Evidence from three inflation targeters". Cambridge University Press.

Bauer, M. D. (2012). Monetary policy and interest rate uncertainty. FRBSF Economic Letter, 38.

Blinder, A. S., Ehrmann, M., Fratzscher, M., De Haan, J., and Jansen, D.-J. (2008). Central bank communication and monetary policy: A survey of theory and evidence. Journal of Economic Literature, 46:910-945.

Detmers, G.-A. and Nautz, D. (2012). The information content of central bank interest rate projections: Evidence from New Zealand. Economic Record, 88(282):323-329.

Ehrmann, M. and Sondermann, D. (2012). The news content of macroeconomic announcements: What if central bank communication becomes stale? International Journal of Central Banking, 8(3).

Ferrero, G. and Secchi, A. (2009). The announcement of monetary policy intentions. Banca d'Italia Temi di discussione, 720.

Goodhart, C. A. E. and Wen, B. L. (2011). Interest rate forecasts: A pathology. International Journal of Central Banking, 7(2):135-171. 
Guender, A. V. and Rimer, O. (2008). The implementation of monetary policy in New Zealand: What factors affect the 90-day bank bill rate? North American Journal of Economics and Finance, 19(2):215-234.

Moessner, R. (2013). Effects of explicit FOMC policy rate guidance on interest rate expectations. Economics Letters, forthcoming.

Moessner, R. and Nelson, W. R. (2008). Central bank policy rate guidance and financial market functioning. International Journal of Central Banking, 4(4):193-226.

Neuenkirch, M. (2012). Managing financial market expectations: The role of central bank transparency and central bank communication. European Journal of Political Economy, 28:1-13.

Rudebusch, G. D. and Williams, J. C. (2008). Asset Prices and Monetary Policy, chapter "Revealing the secrets of the temple: The value of publishing central bank interest rate projections", pages 247-289. National Bureau of Economic Research, Inc.

Swanson, E. T. (2006). Have increases in federal reserve transparency improved private sector interest rate forecasts? Journal of Money, Credit, and Banking, 38(3):791-819.

Winkelmann, L. (2013). Quantitative forward guidance and the predictability of monetary policy - a wavelet based jump detection approach. SFB 649 Discussion Paper Series, forthcoming. 


\section{Appendix}

Figure 3 Interest rate projections and futures rates in New Zealand
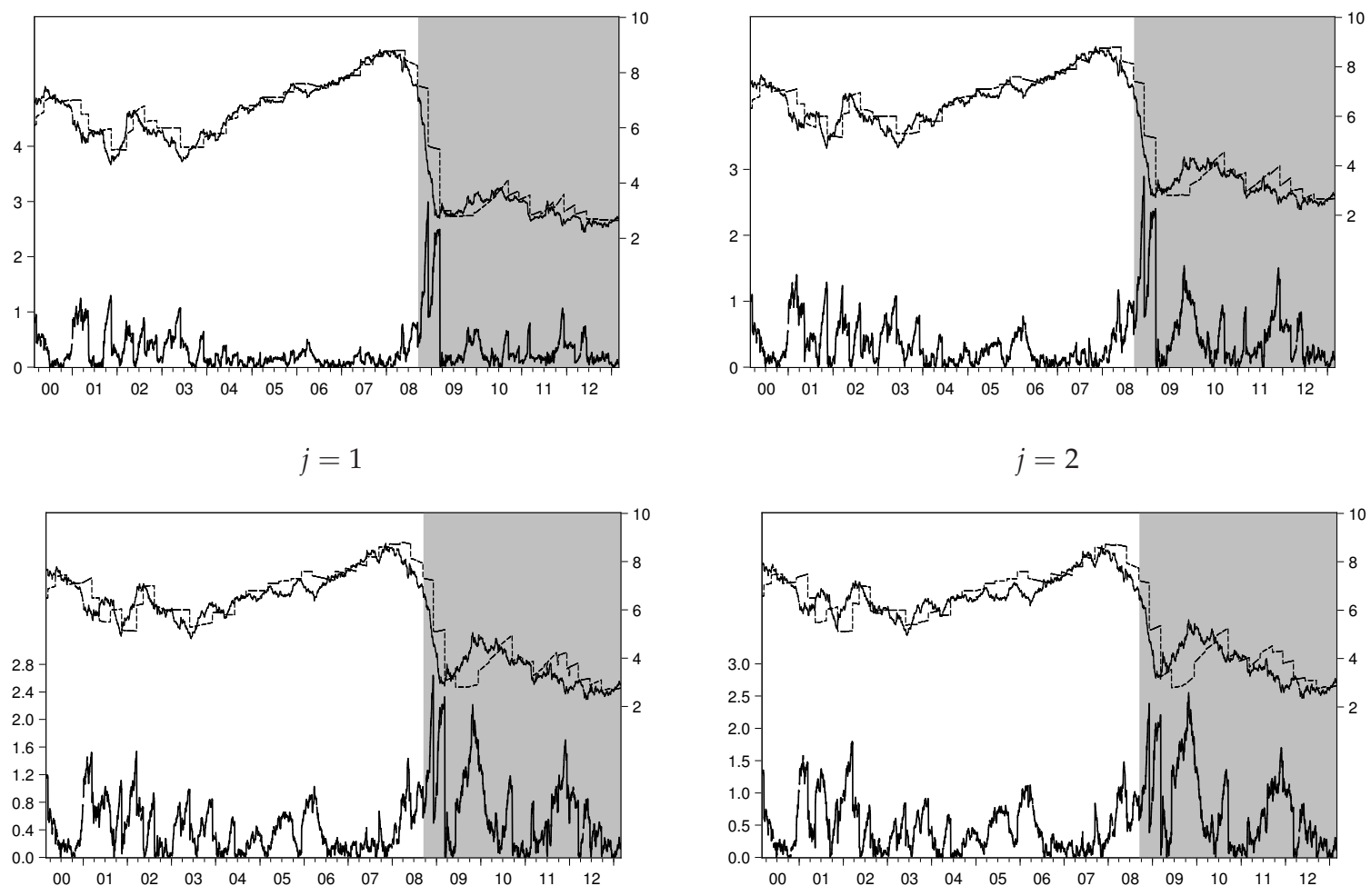

$$
j=3
$$

$j=4$

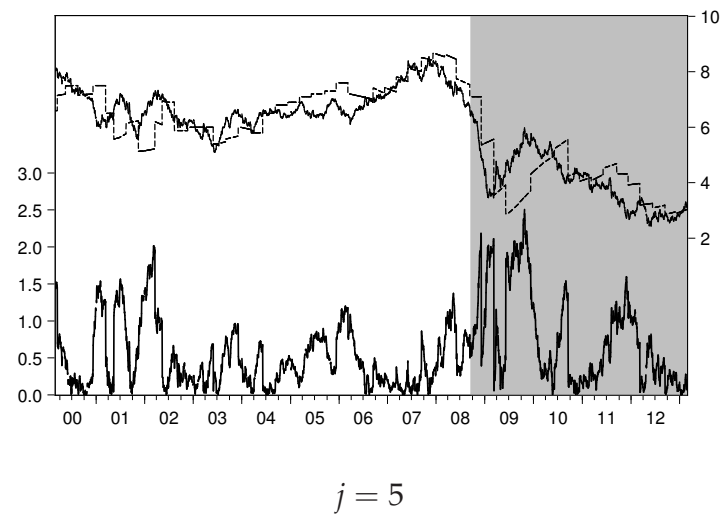

Notes: Futures rates $f_{t}$ and central bank interest rate projections $p_{t}$ (dashed line) at horizons $j=1, \ldots, 5$ as well as the absolute deviation $\left|f_{t}-p_{t}\right|$ (bold line at the bottom, left scale) from March 2000 until February 2013. Data is denoted in $\%$. The light shaded area refers to the period as of September 2008. 
Table 4 The EGARCH model for futures rates: Complete results for the pre-crisis sample

\begin{tabular}{|c|c|c|c|c|c|c|c|c|c|}
\hline \multirow{3}{*}{$j=1$} & & $\alpha$ & $\beta^{M P S}$ & $\beta^{O C R}$ & $\gamma^{U S}$ & $\gamma^{t w i}$ & $\gamma^{e \cos u r}$ & $\delta$ & \\
\hline & $\Delta f_{t}$ & $\begin{array}{c}0.001 \\
(0.001)\end{array}$ & $\begin{array}{c}0.23^{* * *} \\
(0.08)\end{array}$ & $\begin{array}{c}0.10^{* * *} \\
(0.04)\end{array}$ & $\begin{array}{c}0.18^{* * *} \\
(0.01)\end{array}$ & $\begin{array}{l}-0.003^{*} \\
(0.001)\end{array}$ & $\begin{array}{l}0.00003^{*} \\
(0.00002)\end{array}$ & $\begin{array}{c}0.09^{* * *} \\
(0.02)\end{array}$ & \\
\hline & $\log \left(\sigma_{t}^{2}\right)$ & $\begin{array}{c}\omega_{0} \\
-4.96^{* * *} \\
(0.32)\end{array}$ & $\begin{array}{c}\omega_{1} \\
0.39^{* * *} \\
(0.04)\end{array}$ & $\begin{array}{c}\omega_{2} \\
0.01 \\
(0.02)\end{array}$ & $\begin{array}{c}\omega_{3} \\
0.34^{* * *} \\
(0.03)\end{array}$ & $\begin{array}{c}\eta^{\text {OCR }} \\
1.93^{* * *} \\
(0.17)\end{array}$ & $\begin{array}{c}\eta^{M P S} \\
0.14 \\
(0.30)\end{array}$ & $\begin{array}{c}\rho_{\tau} \\
0.30^{* * *} \\
(0.05)\end{array}$ & $\begin{array}{c}\rho_{S} \\
1.98^{* * *} \\
(0.19)\end{array}$ \\
\hline \multirow{3}{*}{$j=2$} & & $\alpha$ & $\beta^{M P S}$ & $\beta^{O C R}$ & $\gamma^{U S}$ & $\gamma^{t w i}$ & $\gamma^{e \cos u r}$ & $\delta$ & \\
\hline & $\Delta f_{t}$ & $\begin{array}{c}0.001 \\
(0.001)\end{array}$ & $\begin{array}{c}0.17^{* * *} \\
(0.06)\end{array}$ & $\begin{array}{c}0.12^{* * *} \\
(0.04)\end{array}$ & $\begin{array}{c}0.25^{* * *} \\
(0.01)\end{array}$ & $\begin{array}{l}-0.002 \\
(0.002)\end{array}$ & $\begin{array}{c}0.00002 \\
(0.00002)\end{array}$ & $\begin{array}{l}0.12^{* * *} \\
(0.02)\end{array}$ & \\
\hline & $\log \left(\sigma_{t}^{2}\right)$ & $\begin{array}{c}\omega_{0} \\
-4.12^{* * *} \\
(0.32)\end{array}$ & $\begin{array}{c}\omega_{1} \\
0.48^{* * *} \\
(0.04)\end{array}$ & $\begin{array}{c}\omega_{2} \\
0.02 \\
(0.02)\end{array}$ & $\begin{array}{c}\omega_{3} \\
0.35^{* * *} \\
(0.04)\end{array}$ & $\begin{array}{c}\eta^{\text {OCR }} \\
1.53^{* * *} \\
(0.21)\end{array}$ & $\begin{array}{c}\eta^{M P S} \\
0.42 \\
(0.32)\end{array}$ & $\begin{array}{c}\rho_{\tau} \\
0.19^{* * *} \\
(0.05)\end{array}$ & $\begin{array}{c}\rho_{s} \\
1.33^{* * *} \\
(0.11)\end{array}$ \\
\hline \multirow{3}{*}{$j=3$} & & $\alpha$ & $\beta^{M P S}$ & $\beta^{O C R}$ & $\gamma^{U S}$ & $\gamma^{t w i}$ & $\gamma^{e \cos u r}$ & $\delta$ & \\
\hline & $\Delta f_{t}$ & $\begin{array}{c}0.001 \\
(0.001)\end{array}$ & $\begin{array}{l}0.12^{* *} \\
(0.05)\end{array}$ & $\begin{array}{c}0.12^{* * *} \\
(0.04)\end{array}$ & $\begin{array}{c}0.28^{* * *} \\
(0.01)\end{array}$ & $\begin{array}{l}-0.002 \\
(0.002)\end{array}$ & $\begin{array}{c}0.00001 \\
(0.00002)\end{array}$ & $\begin{array}{l}0.11^{* * *} \\
(0.02)\end{array}$ & \\
\hline & $\log \left(\sigma_{t}^{2}\right)$ & $\begin{array}{c}\omega_{0} \\
-4.65^{* * *} \\
(0.33)\end{array}$ & $\begin{array}{c}\omega_{1} \\
0.40^{* * *} \\
(0.05)\end{array}$ & $\begin{array}{c}\omega_{2} \\
0.07^{* * *} \\
(0.02)\end{array}$ & $\begin{array}{c}\omega_{3} \\
0.36^{* * *} \\
(0.04)\end{array}$ & $\begin{array}{c}\eta^{O C R} \\
1.43^{* * *} \\
(0.24)\end{array}$ & $\begin{array}{c}\eta^{M P S} \\
0.52 \\
(0.37)\end{array}$ & $\begin{array}{c}\rho_{\tau} \\
0.18^{* * *} \\
(0.06)\end{array}$ & $\begin{array}{c}\rho_{s} \\
1.25^{* * *} \\
(0.12)\end{array}$ \\
\hline \multirow{3}{*}{$j=4$} & & $\alpha$ & $\beta^{M P S}$ & $\beta^{O C R}$ & $\gamma^{U S}$ & $\gamma^{t w i}$ & $\gamma^{e \cos u r}$ & $\delta$ & \\
\hline & $\Delta f_{t}$ & $\begin{array}{l}0.0002 \\
(0.001)\end{array}$ & $\begin{array}{l}0.09^{* *} \\
(0.04)\end{array}$ & $\begin{array}{c}0.13^{* * *} \\
(0.03)\end{array}$ & $\begin{array}{c}0.31^{* * *} \\
(0.01)\end{array}$ & $\begin{array}{l}-0.002 \\
(0.002)\end{array}$ & $\begin{array}{c}0.00001 \\
(0.00002)\end{array}$ & $\begin{array}{c}0.10^{* * *} \\
(0.02)\end{array}$ & \\
\hline & $\log \left(\sigma_{t}^{2}\right)$ & $\begin{array}{c}\omega_{0} \\
-3.64^{* * *} \\
(0.28)\end{array}$ & $\begin{array}{c}\omega_{1} \\
0.53^{* * *} \\
(0.04)\end{array}$ & $\begin{array}{c}\omega_{2} \\
0.06^{* * *} \\
(0.02)\end{array}$ & $\begin{array}{c}\omega_{3} \\
0.39 * * * \\
(0.04)\end{array}$ & $\begin{array}{c}\eta^{\text {OCR }} \\
1.13^{* * *} \\
(0.20)\end{array}$ & $\begin{array}{l}\eta^{M P S} \\
0.66^{* *} \\
(0.31)\end{array}$ & $\begin{array}{c}\rho_{\tau} \\
0.05 \\
(0.06)\end{array}$ & $\begin{array}{c}\rho_{S} \\
0.72^{* * *} \\
(0.09)\end{array}$ \\
\hline \multirow{3}{*}{$j=5$} & & $\alpha$ & $\beta^{M P S}$ & $\beta^{O C R}$ & $\gamma^{U S}$ & $\gamma^{t w i}$ & $\gamma^{e \cos u r}$ & $\delta$ & \\
\hline & $\Delta f_{t}$ & $\begin{array}{l}0.0004 \\
(0.001)\end{array}$ & $\begin{array}{l}0.07^{* *} \\
(0.03)\end{array}$ & $\begin{array}{c}0.12^{* * *} \\
(0.03)\end{array}$ & $\begin{array}{c}0.34^{* * *} \\
(0.01)\end{array}$ & $\begin{array}{l}-0.001 \\
(0.002)\end{array}$ & $\begin{array}{l}-0.00001 \\
(0.00002)\end{array}$ & $\begin{array}{c}0.09^{* * *} \\
(0.02)\end{array}$ & \\
\hline & $\log \left(\sigma_{t}^{2}\right)$ & $\begin{array}{c}\omega_{0} \\
-3.45^{* * *} \\
(0.28)\end{array}$ & $\begin{array}{c}\omega_{1} \\
0.54^{* * *} \\
(0.04)\end{array}$ & $\begin{array}{c}\omega_{2} \\
0.05^{* *} \\
(0.02)\end{array}$ & $\begin{array}{c}\omega_{3} \\
0.45^{* * *} \\
(0.04)\end{array}$ & $\begin{array}{c}\eta^{\text {OCR }} \\
0.96^{* * *} \\
(0.21)\end{array}$ & $\begin{array}{l}\eta^{M P S} \\
0.79 * * \\
(0.31)\end{array}$ & $\begin{array}{c}\rho_{\tau} \\
-0.01 \\
(0.07)\end{array}$ & $\begin{array}{c}\rho_{s} \\
0.49^{* * *} \\
(0.08)\end{array}$ \\
\hline
\end{tabular}

Notes: The table shows the empirical results from equations (1) and 2]:

$$
\begin{aligned}
& \Delta f_{t}^{j}=\alpha+\beta^{M P S, j} \cdot D_{t}^{M P S}\left(p_{t}^{j}-f_{t-1}^{j}\right)+\beta^{O C R, j} \cdot D_{t}^{O C R}\left(r_{t}^{O C R}-r_{t-1}^{30}\right)+\gamma^{U S, j} \Delta r_{t}^{U S, 2 y}+\gamma^{t w i, j} \Delta t w i_{t}+\gamma^{e c o s u r, j} s_{t}^{e c c}+\delta^{j} \Delta f_{t-1}^{j}+\varepsilon_{t} \\
& \log \left(\sigma_{t}^{2, j}\right)=\omega_{0}^{j}+\omega_{1}^{j} \cdot \log \left(\sigma_{t-1}^{2, j}\right)+\omega_{2}^{j} \cdot\left|\frac{\varepsilon_{t-1}^{j}}{\sigma_{t-1}^{j}}\right|+\omega_{3}^{j} \cdot \frac{\varepsilon_{t-1}^{j}}{\sigma_{t-1}^{j}}+\eta^{O C R} D_{t}^{O C R}+\eta^{M P S} D_{t}^{M P S}+\rho_{\tau}^{j} \tau_{t}+\rho_{s}^{j}\left|f^{j}-p^{j}\right|_{t-1}\left(1-\tau_{t}\right)
\end{aligned}
$$

For an explanation of the variables refer to Table 6 The sample covers business days from February 24, 2000 until September $12,2008 .{ }^{* * *}\left({ }^{* *}\right)\left[{ }^{*}\right]$ denotes significance at the $1 \%(5 \%)[10 \%]$ level; standard errors in parentheses. 
Table 5 The EGARCH model for futures rates: Complete results for the crisis sample

\begin{tabular}{|c|c|c|c|c|c|c|c|c|c|}
\hline \multirow{3}{*}{$j=1$} & & $\alpha$ & $\beta^{M P S}$ & $\beta^{O C R}$ & $\gamma^{U S}$ & $\gamma^{t w i}$ & $\gamma^{e \cos u r}$ & $\delta$ & \\
\hline & $\Delta f_{t}$ & $\begin{array}{c}0.001 \\
(0.001)\end{array}$ & $\begin{array}{l}-0.05 \\
(0.04)\end{array}$ & $\begin{array}{c}0.09^{* * *} \\
(0.03)\end{array}$ & $\begin{array}{c}0.08^{* * *} \\
(0.01)\end{array}$ & $\begin{array}{c}0.003 \\
(0.002)\end{array}$ & $\begin{array}{l}0.00004^{* *} \\
(0.00002)\end{array}$ & $\begin{array}{c}0.14^{* * *} \\
(0.04)\end{array}$ & \\
\hline & $\log \left(\sigma_{t}^{2}\right)$ & $\begin{array}{c}\omega_{0} \\
-1.35^{* * *} \\
(0.12)\end{array}$ & $\begin{array}{c}\omega_{1} \\
0.88^{* * *} \\
(0.01)\end{array}$ & $\begin{array}{c}\omega_{2} \\
0.02 \\
(0.02)\end{array}$ & $\begin{array}{c}\omega_{3} \\
0.37^{* * *} \\
(0.03)\end{array}$ & $\begin{array}{c}\eta^{O C R} \\
1.35^{* * *} \\
(0.24)\end{array}$ & $\begin{array}{l}\eta^{M P S} \\
-0.57^{*} \\
(0.32)\end{array}$ & $\begin{array}{c}\rho_{\tau} \\
0.26^{* * *} \\
(0.05)\end{array}$ & $\begin{array}{c}\rho_{s} \\
0.52^{* * *} \\
(0.07)\end{array}$ \\
\hline \multirow{3}{*}{$j=2$} & & $\alpha$ & $\beta^{M P S}$ & $\beta^{O C R}$ & $\gamma^{U S}$ & $\gamma^{t w i}$ & $\gamma^{e \cos u r}$ & $\delta$ & \\
\hline & $\Delta f_{t}$ & $\begin{array}{r}-0.0002 \\
(0.001)\end{array}$ & $\begin{array}{l}-0.05 \\
(0.03)\end{array}$ & $\begin{array}{l}0.08^{* *} \\
(0.04)\end{array}$ & $\begin{array}{c}0.20 * * * \\
(0.02)\end{array}$ & $\begin{array}{l}0.01^{* *} \\
(0.003)\end{array}$ & $\begin{array}{c}0.00003 \\
(0.00003)\end{array}$ & $\begin{array}{c}0.10^{* * *} \\
(0.03)\end{array}$ & \\
\hline & $\log \left(\sigma_{t}^{2}\right)$ & $\begin{array}{c}\omega_{0} \\
-1.40^{* * *} \\
(0.17)\end{array}$ & $\begin{array}{c}\omega_{1} \\
0.84^{* * *} \\
(0.02)\end{array}$ & $\begin{array}{c}\omega_{2} \\
0.03 \\
(0.02)\end{array}$ & $\begin{array}{c}\omega_{3} \\
0.23^{* * *} \\
(0.03)\end{array}$ & $\begin{array}{c}\eta^{O C R} \\
1.21^{* * *} \\
(0.25)\end{array}$ & $\begin{array}{l}\eta^{M P S} \\
-0.61^{*} \\
(0.34)\end{array}$ & $\begin{array}{c}\rho_{\tau} \\
0.25^{* * *} \\
(0.05)\end{array}$ & $\begin{array}{c}\rho_{s} \\
0.44^{* * *} \\
(0.06)\end{array}$ \\
\hline \multirow{3}{*}{$j=3$} & & $\alpha$ & $\beta^{M P S}$ & $\beta^{O C R}$ & $\gamma^{U S}$ & $\gamma^{t w i}$ & $\gamma^{e \cos u r}$ & $\delta$ & \\
\hline & $\Delta f_{t}$ & $\begin{array}{l}-0.001 \\
(0.001)\end{array}$ & $\begin{array}{l}-0.04 \\
(0.02)\end{array}$ & $\begin{array}{c}0.05 \\
(0.05)\end{array}$ & $\begin{array}{c}0.30^{* * *} \\
(0.03)\end{array}$ & $\begin{array}{l}0.01^{* * *} \\
(0.003)\end{array}$ & $\begin{array}{c}0.00002 \\
(0.00003)\end{array}$ & $\begin{array}{c}0.09^{* * *} \\
(0.03)\end{array}$ & \\
\hline & $\log \left(\sigma_{t}^{2}\right)$ & $\begin{array}{c}\omega_{0} \\
-1.42^{* * *} \\
(0.21)\end{array}$ & $\begin{array}{c}\omega_{1} \\
0.83^{* * *} \\
(0.03)\end{array}$ & $\begin{array}{c}\omega_{2} \\
0.05^{* *} \\
(0.02)\end{array}$ & $\begin{array}{c}\omega_{3} \\
0.23^{* * *} \\
(0.03)\end{array}$ & $\begin{array}{c}\eta^{\text {OCR }} \\
1.20^{* * *} \\
(0.25)\end{array}$ & $\begin{array}{c}\eta^{M P S} \\
-0.72^{* *} \\
(0.36)\end{array}$ & $\begin{array}{c}\rho_{\tau} \\
0.24^{* * *} \\
(0.05)\end{array}$ & $\begin{array}{c}\rho_{s} \\
0.31^{* * *} \\
(0.05)\end{array}$ \\
\hline \multirow{3}{*}{$j=4$} & & $\alpha$ & $\beta^{M P S}$ & $\beta^{O C R}$ & $\gamma^{U S}$ & $\gamma^{t w i}$ & $\gamma^{e \cos u r}$ & $\delta$ & \\
\hline & $\Delta f_{t}$ & $\begin{array}{l}-0.002 \\
(0.002)\end{array}$ & $\begin{array}{c}-0.06^{* * *} \\
(0.02)\end{array}$ & $\begin{array}{l}0.10^{*} \\
(0.05)\end{array}$ & $\begin{array}{c}0.31^{* * *} \\
(0.03)\end{array}$ & $\begin{array}{l}0.01^{* * *} \\
(0.003)\end{array}$ & $\begin{array}{c}0.0000001 \\
(0.00003)\end{array}$ & $\begin{array}{c}0.10^{* * *} \\
(0.03)\end{array}$ & \\
\hline & $\log \left(\sigma_{t}^{2}\right)$ & $\begin{array}{c}\omega_{0} \\
-1.46^{* * *} \\
(0.24)\end{array}$ & $\begin{array}{c}\omega_{1} \\
0.82^{* * *} \\
(0.03)\end{array}$ & $\begin{array}{c}\omega_{2} \\
0.03 \\
(0.02)\end{array}$ & $\begin{array}{c}\omega_{3} \\
0.26^{* * *} \\
(0.03)\end{array}$ & $\begin{array}{c}\eta^{\text {OCR }} \\
1.08^{* * *} \\
(0.24)\end{array}$ & $\begin{array}{l}\eta^{M P S} \\
-0.39 \\
(0.35)\end{array}$ & $\begin{array}{c}\rho_{\tau} \\
0.20^{* * *} \\
(0.06)\end{array}$ & $\begin{array}{c}\rho_{s} \\
0.25^{* * *} \\
(0.05)\end{array}$ \\
\hline \multirow{3}{*}{$j=5$} & & $\alpha$ & $\beta^{M P S}$ & $\beta^{O C R}$ & $\gamma^{U S}$ & $\gamma^{t w i}$ & $\gamma^{e \cos u r}$ & $\delta$ & \\
\hline & $\Delta f_{t}$ & $\begin{array}{l}-0.002 \\
(0.002)\end{array}$ & $\begin{array}{c}-0.07^{* * *} \\
(0.01)\end{array}$ & $\begin{array}{l}0.09^{*} \\
(0.05)\end{array}$ & $\begin{array}{c}0.35^{* * *} \\
(0.03)\end{array}$ & $\begin{array}{l}0.01^{* * *} \\
(0.003)\end{array}$ & $\begin{array}{c}0.00001 \\
(0.00003)\end{array}$ & $\begin{array}{l}0.08^{* *} \\
(0.04)\end{array}$ & \\
\hline & $\log \left(\sigma_{t}^{2}\right)$ & $\begin{array}{c}\omega_{0} \\
-1.28^{* * *} \\
(0.24)\end{array}$ & $\begin{array}{c}\omega_{1} \\
0.84^{* * *} \\
(0.03)\end{array}$ & $\begin{array}{c}\omega_{2} \\
0.06^{* * *} \\
(0.02)\end{array}$ & $\begin{array}{c}\omega_{3} \\
0.23^{* * *} \\
(0.04)\end{array}$ & $\begin{array}{c}\eta^{O C R} \\
0.96^{* * *} \\
(0.22)\end{array}$ & $\begin{array}{l}\eta^{M P S} \\
-0.31 \\
(0.30)\end{array}$ & $\begin{array}{c}\rho_{\tau} \\
0.15^{* * *} \\
(0.04)\end{array}$ & $\begin{array}{c}\rho_{s} \\
0.19^{* * *} \\
(0.04)\end{array}$ \\
\hline
\end{tabular}

Notes: The table shows the empirical results from equations (1) and 2]:

$$
\begin{gathered}
\Delta f_{t}^{j}=\alpha+\beta^{M P S, j} \cdot D_{t}^{M P S}\left(p_{t}^{j}-f_{t-1}^{j}\right)+\beta^{O C R, j} \cdot D_{t}^{O C R}\left(r_{t}^{O C R}-r_{t-1}^{30}\right)+\gamma^{U S, j} \Delta r_{t}^{U S, 2 y}+\gamma^{t w w i, j} \Delta t w i_{t}+\gamma^{e c o s u u r, j} s_{t}^{e c o}+\delta \delta^{j} \Delta f_{t-1}^{j}+\varepsilon_{t} \\
\log \left(\sigma_{t}^{2, j}\right)=\omega_{0}^{j}+\omega_{1}^{j} \cdot \log \left(\sigma_{t-1}^{2, j}\right)+\omega_{2}^{j} \cdot\left|\frac{\varepsilon_{t-1}^{j}}{\sigma_{t-1}^{j}}\right|+\omega_{3}^{j} \cdot \frac{\varepsilon_{t-1}^{j}}{\sigma_{t-1}^{j}}+\eta^{O C R} D_{t}^{O C R}+\eta^{M P S} D_{t}^{M P S}+\rho_{\tau}^{j} \tau_{t}+\rho_{s}^{j}\left|f^{j}-p^{j}\right|_{t-1}\left(1-\tau_{t}\right)
\end{gathered}
$$

For an explanation of the variables refer to Table 6 The sample covers business days from September 15, 2008 until February $28,2013 .{ }^{* * *}\left({ }^{* *}\right)\left[{ }^{*}\right]$ denotes significance at the $1 \%(5 \%)[10 \%]$ level; standard errors in parentheses. 
Table 6 List of variables

\begin{tabular}{ll}
\hline \hline$f_{t}^{j}$ & $\begin{array}{l}\text { future rate as a proxy for market expectations about the 90-day rate during the } \\
\text { quarter } j \text { quarter ahead }\end{array}$ \\
$\Delta f_{t}^{j}$ & $\begin{array}{l}\text { daily change of futures rates } \\
\text { central bank interest rate projection of the 90-day rate during the quarter } j \text { quar- } \\
p_{t}^{j}\end{array}$ \\
& $\begin{array}{l}\text { ters ahead } \\
\text { time measure for the distance to the recent release of interest rate projections, }\end{array}$ \\
$\tau_{t}$ & $0 \leq \tau_{t} \leq 1$
\end{tabular}

